\title{
Polyphenoles extraction from the potato peel and their utilization in biscuiut
}

\author{
Mohammad Taimoor Khan ${ }^{1}$, Abdul Sattar Shah ${ }^{1 *}$, Naeem Safdar ${ }^{2}$, \\ Sumayya Rani ${ }^{1}$, Haris Bilal ${ }^{3}$, Malik Muhammad Hashim ${ }^{4}$, Abdul Basir ${ }^{1}$, \\ Ziaur Rahman ${ }^{1}$ and Syed Abdul Majeed Shah ${ }^{1}$ \\ 1. Department of Agriculture, The University of Swabi, Anbar Swabi-Pakistan \\ 2. National Agricultural Research Centre (NARC), Islamabad-Pakistan \\ 3. Department of Food Science and Technology The University of Agriculture Peshawar-Pakistan \\ 4. Department of Food Science and Technology, Faculty of Agriculture, Gomal University, D.I. Khan-Pakistan \\ *Corresponding author's email: shahjee15@gmail.com; shahjee515@yahoo.com
}

Citation

Mohammad Taimoor Khan, Abdul Sattar Shah, Naeem Safdar, Sumayya Rani, Haris Bilal, Malik Muhammad Hashim, Abdul Basir, Ziaur Rahman and Syed Abdul Majeed Shah. Polyphenoles extraction from the potato peel and their utilization in biscuiut. Pure and Applied Biology. Vol. 6, Issue 4, pp1269-1275.

http://dx.doi.org/10.19045/bspab.2017.600135

\begin{tabular}{llll}
\hline \hline Received: $12 / 06 / 2017$ & Revised: 26/09/2017 & Accepted: 29/09/2017 & Online First: 04/10/2017 \\
\hline
\end{tabular}

\section{Abstract}

The objectives of this research work was to investigate the effects of polyphenols on biscuits extracted from potato peel. Biscuits were prepared according to the formula and polyphenol were sprayedat different proportions $(0 \%, 0.5 \%, 1 \%$, and $1.5 \%)$ extracted from the potato peel of diamante variety and were evaluated for total polyphenols, moisture, ash and sensory (Colour, flavour, texture and Overall Acceptability) characteristics. The moisture content of the sprayed biscuits increased, whereas ash content of the biscuits remained in the same range with increase in concentration of polyphenols. The sensory results showed that a maximum of $1.5 \%$ polyphenols can be sprayed to prepare acceptable quality biscuits. These biscuits can be used for anti-cancer effects and can be safely stored in polypropylene bags for a longer period without any appreciable change in the sensory properties.

Keywords: Antioxidant; Anti-cancer biscuit; Polyphenol; Phytochemicals; Sensory quality

\section{Introduction}

Potatoes are significant source of natural antioxidants and exhibit antioxidant activity as demonstrated in recent time by many authors. Studies have indicated that these phytochemicals have high free-radical scavenging activity, which helps to reduce the risk of chronic diseases and age-related neuronal degeneration Bibliography [1].

Potato peel has been proved medicinally important as it contains phenolic, polyphenolic compound, anthocyanins, nonanthocyanin flavonoids and glycoalkaloids which are health beneficial having antioxidental and anti-bacterial properties. Many products of industrial importance like amylases, citric acid and prebiotics etc., are being produced by using potato waste as microbial substrate [2]. .

Conventionally, antioxidants from potato peels are extracted using traditional methods such as Soxhlet and heat reflux. These methods have been associated with longer extraction times, high solvent consumption and increased risk of degradation of heatlabile constituents. Bibliography [3] recently 
evaluated a novel microwave-assisted extraction (MAE) process which used microwave energy to heat the solvent and the sample in order to extract a specific compound from the sample into the solvent. MAE offers many advantages such as shorter extraction times, lower solvent consumption, and higher selectivity towards target molecules.

MAE has been used to extract bioactive compounds from a wide variety of plants and natural residues: secoisolariciresinol diglucoside from flaxseeds (Linum usitatissimum L.), resveratrol and phenolic antioxidants from peanut (Arachis hypogcea L.) skin , flavonoids from Chinese herbs, solanesol from potato leaves and stems, pigments from paprika (Capsicum annuит L.), and pectin from apple (Malus domestica) pomades . Phenolic compounds with high antioxidant activity have been identified in several agro-industrial by-products. Winery by-products can be used to extract anthocyanins and flavonols which have been reported to possess antibacterial, antiinflammatory, anti-carcinogenic and antioxidant activities [4].

Keeping in view the importance of polyphenoles present research were conducted to find out the best combination of temperature, solvent type and solvent concentration for the maximum extraction of polyphenols by using maceration and ultrasound technique. To prepare functional food (biscuit) containing extracted polyphenols from potato peel.

\section{Material and methods}

Potatoes were washed, dried and peeled first. Then the peels were cut into small pieces and dried by three different methods i.e. by using hot air oven for 24 hours, by microwave oven for 5 minutes and by sun drying for 2 days. Best results were obtained by microwave drying. Then the dried sample were milled into fine powder by grinding in Cyclotec mill, packed in air-tight polyethylene zip bags and stored at refrigerated temperature till further analysis. Ultrasonic bath was employed for the extraction of polyphenols from potato peel powder. Polyphenols were then separated from the ethanol solution by evaporating the solvent using the rotary evaporator. Total phenols were determined by the method of [5] with slight modification. The extracted polyphenols were mixed in the sugar solutions so that their astringent effect may be overcome. Biscuits were prepared by using sugar, flour, shortening, egg, baking powder, milk and baking powder. The biscuits were divided into four parts for the spray of four different solutions with different concentration of polyphenols.

\section{Preparation of biscuits}

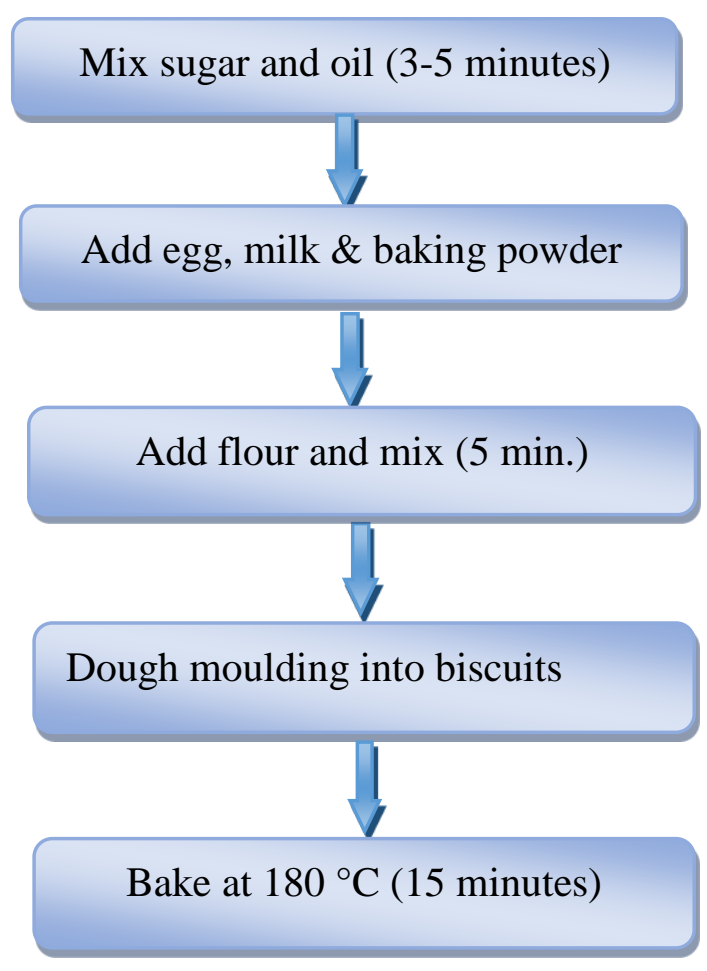

\section{Determination of moisture}

Moisture content of biscuits sprayed with polyphenol solution were determined using the standard method [6]. 


\section{Determination of ash}

Ash percent of biscuits sprayed with polyphenol solution were determined using the standard method [6].

\section{Total phenols determination}

Total phenols of biscuits sprayed with polyphenol solution were determined by the method of [7] with slight modification.

\section{Sensory evaluation}

Sensory evaluation (Colour, flavour, texture and Overall Acceptability) of the biscuits sprayed with polyphenol solution was done by using a 9 point Hedonic Scale as described by [8].

\section{Results and discussion}

Total phenols of potato peel powder are depicted in (Table 1). The biscuits prepared by adding different concentrations of polyphenols were tested for the total phenols. Total phenols were least in the sundried sample (9.82 mg gallic acid equivalent /g of extract) while they were observed maximum in the microwave assisted drying of peel powder (12.81 mg gallic acid equivalent $/ \mathrm{g}$ of extract). Hot air dried sample also showed better results as compared to sun drying. Total phenols calibration curve are shown in figure 1 .

Table 1. Total phenols of potato peel powder

\begin{tabular}{|l|c|}
\hline \multicolumn{1}{|c|}{ Drying Methods } & Total Phenols (mg Gallic acid equivalent /g of extract) \\
\hline Oven Drying (OD) & $10.76 \pm 0.55$ \\
\hline Sun Drying (SD) & $9.82 \pm 0.42$ \\
\hline Microwave Drying (MW) & $12.81 \pm 0.62$ \\
\hline
\end{tabular}

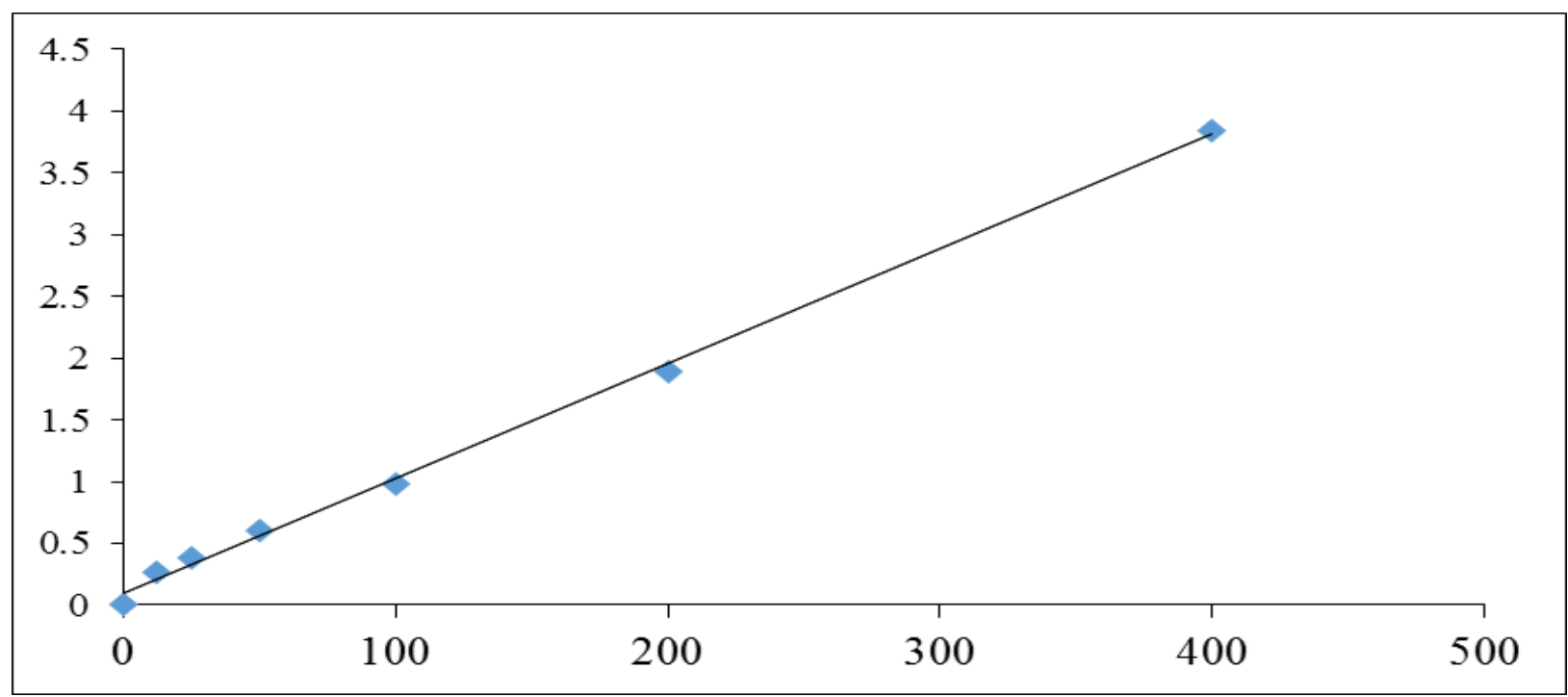

Figure 1. Total phenols calibration curve

The biscuits prepared by adding different concentrations of polyphenols were tested for the total phenols are mentioned in table 2 . Total phenols were least in the first treatment $\mathrm{T}_{0}$ (7.42mg Gallic acid equivalent/biscuit). While $\mathrm{T}_{1}$ has a little bit increased percentage which was added with 0.5 grams of polyphenols. In $\mathrm{T}_{2}$, which was having $1 \mathrm{~g}$. polyphenols, more increased total phenols were noted $(26.53 \mathrm{mg}$ Gallic acid equivalent/biscuit). The highest total phenols were in $T_{3}$. Overall increasing trend was observed in the total phenols content of the biscuits. 
Total phenols calibration curve are shown in

(Figure 2).

Table 2. Total phenols of biscuits

\begin{tabular}{|c|c|}
\hline Treatments & Total Phenols (mg Gallic acid equivalent/biscuit) \\
\hline $\mathrm{T}_{0}$ & $7.42 \pm 0.17$ \\
\hline $\mathrm{T}_{1}$ & $16.47 \pm 0.31$ \\
\hline $\mathrm{T}_{2}$ & $26.53 \pm 0.47$ \\
\hline $\mathrm{T}_{3}$ & $37.52 \pm 0.51$ \\
\hline
\end{tabular}

$\mathrm{T}_{0}=$ Control biscuits without polyphenols extract

$\mathrm{T}_{1}=$ Biscuits with $0.5 \mathrm{~g}$. polyphenols

$\mathrm{T}_{2}=$ Biscuits with $1 \mathrm{~g}$. polyphenols

$\mathrm{T}_{3}=$ Biscuits with $1.5 \mathrm{~g}$. polyphenols

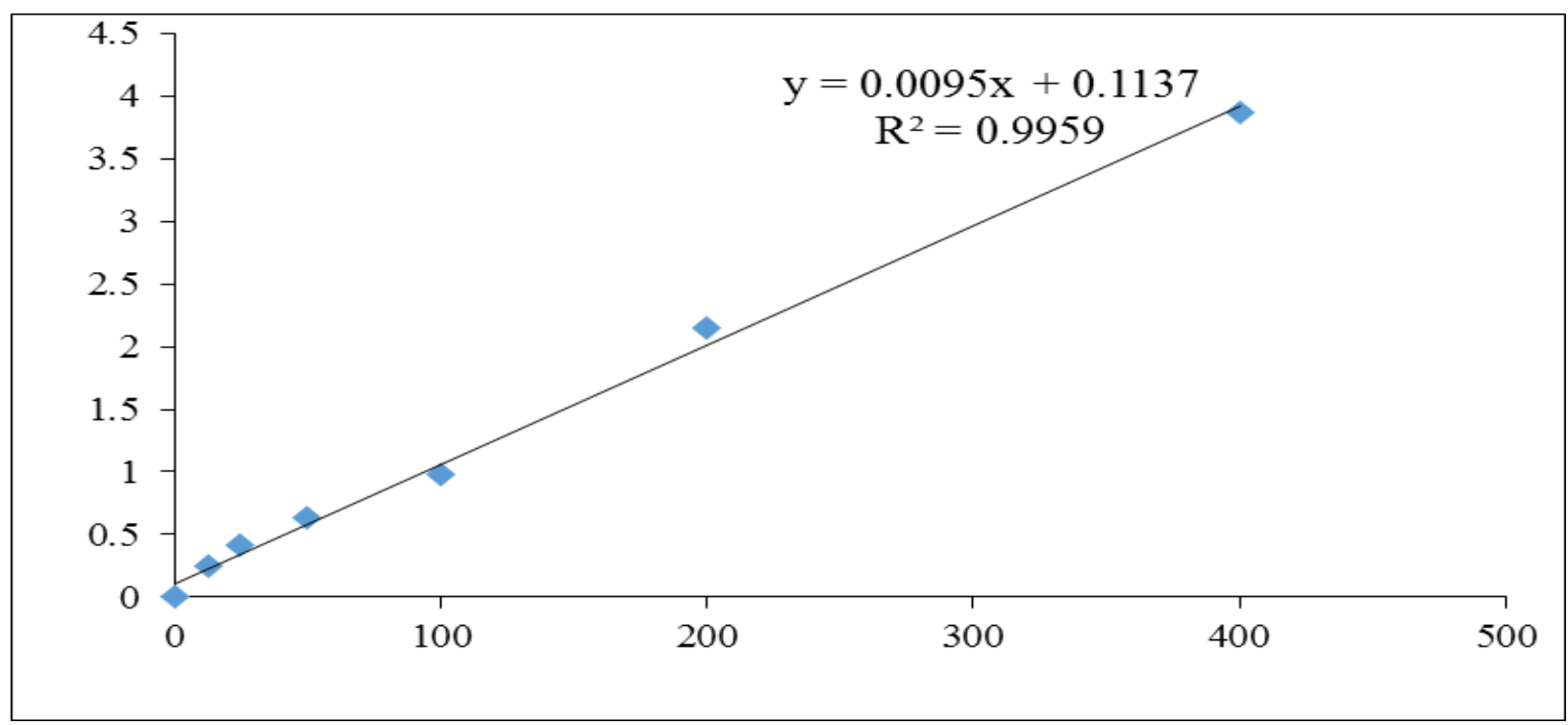

Figure 2. Total phenols calibration curve

The biscuits prepared by adding different concentrations of polyphenols were tested for the moisture content in the oven is depicted in Table 3. The moisture was least in the first treatment $\mathrm{T}_{0}$ (without phenolic extract) in it $(5.17 \%)$ but it was very close to the standard biscuit's moisture. While $T_{1}$ has a little bit increased percentage which was added with 0.5 grams of polyphenols. In $T_{2}$, which was having $1 \mathrm{~g}$. polyphenols, a sudden increase in the moisture was seen (7.15). The highest moisture percentage was in $T_{3}$. An increasing trend was seen in the biscuits with the increase in the number of polyphenols. [9, 10] reported the improvement in moisture content and nutritional quality of bread and cookies with the incorporation of mango dietary fiber which contain polyphenols, carotenoids and dietary fiber obtained from unripe mango fruit. 
Table 3. Moisture determination

\begin{tabular}{|l|l|l|l|l|}
\hline Analysis & $\mathbf{T}_{\mathbf{0}}$ & $\mathbf{T}_{\mathbf{1}}$ & $\mathbf{T}_{\mathbf{2}}$ & $\mathbf{T}_{\mathbf{3}}$ \\
\hline Moisture & $5.17 \pm 0.18 \%$ & $5.22 \pm 0.18 \%$ & $7.15 \pm 0.20 \%$ & $7.74 \pm 0.21 \%$ \\
\hline
\end{tabular}

$\mathrm{T}_{0}=$ Control biscuits without polyphenols extract

$\mathrm{T}_{1}=$ Biscuits with $0.5 \mathrm{~g}$. polyphenols

$\mathrm{T}_{2}=$ Biscuits with $1 \mathrm{~g}$. polyphenols

$\mathrm{T}_{3}=$ Biscuits with $1.5 \mathrm{~g}$. polyphenols

The ash contents were determined to check the total mineral contents in all the four treatments of biscuits are shown in Table 4 . Mineral percentage of all treatments was very less. The highest percentage was observed in $\mathrm{T}_{3}(0.35 \%)$ while the lowest was seen in $\mathrm{T}_{1}$ $(0.30 \%)$.However, there was no increasing or decreasing trend in the four treatments with the increase in polyphenols concentration.
All the four treatments had an average of $0.30 \%$ ash with the increase of very minute quantity. Ash was noted within the range of 0.30 to 0.35 for all. Treatments have nonsignificant effect on ash content. [11] reported that mango peel is rich in soluble dietary fiber (pectin) and have no effect on ash content.

Table 4. Ash determination

\begin{tabular}{|c|l|l|l|l|}
\hline Analysis & $\mathbf{T}_{\mathbf{0}}$ & $\mathbf{T}_{\mathbf{1}}$ & $\mathbf{T}_{\mathbf{2}}$ & $\mathbf{T}_{\mathbf{3}}$ \\
\hline Ash & $0.32 \pm 0.03 \%$ & $0.30 \pm 0.03 \%$ & $0.33 \pm 0.05 \%$ & $0.35 \pm 0.04 \%$ \\
\hline
\end{tabular}

$\mathrm{T}_{0}=$ Control biscuits without polyphenols extract

$\mathrm{T}_{1}=$ Biscuits with $0.5 \mathrm{~g}$. polyphenols

$\mathrm{T}_{2}=$ Biscuits with $1 \mathrm{~g}$. polyphenols

$\mathrm{T}_{3}=$ Biscuits with $1.5 \mathrm{~g}$. polyphenols

\section{Sensory evaluation of biscuits}

Biscuits were analyzed for sensory evaluation is depicted in Table 5. The biscuits prepared by the addition of different concentrations of polyphenols as well as controlled were presented to the panel of judges to offer score of the product according to their liking preference using 9-point hedonic scale [12]. All the four treatments were within good acceptability range. However, the color of the biscuits with the highest concentration of polyphenols achieved highest score (7.52) of $T_{3}$. However, all the other treatments $\mathrm{T}_{0}, \mathrm{~T}_{1}$ and $\mathrm{T}_{2}$ got $6.73,6.67,6.81$ score respectively. The taste of treatments $\mathrm{T}_{2}$ got 6.73 and $\mathrm{T}_{3}$ got 6.95 score which was highest among the four treatments. While that of $\mathrm{T}_{1}$ also got the same score as $\mathrm{T}_{2}$ got (6.73). However, the lowest ranking on the hedonic scale (6.51) on taste was noted for $T_{0}$ (controlled). [13, 14] observed that the biscuits which are rich in polyphenols, these are substrates for the enzymes. Therefore, yellowness of the biscuits may be decreased due to the enzymatic browning.

The texture of biscuits achieved highest score (6.86) when it was prepared by adding the highest polyphenol concentration $\left(\mathrm{T}_{3}\right)$, followed by the biscuits prepared by adding zero percent polyphenols $\left(\mathrm{T}_{0}\right)$. However, the lowest ranking on the hedonic scale (6.51) for texture was noted for the biscuits of treatment $\mathrm{T}_{1}$. These results were similar with the finding of [15], who also observed that the texture was improved with the increase of polyphenol. 
Table 5. Sensory evaluation of biscuits

\begin{tabular}{|l|l|l|l|l|}
\hline Parameter & $\mathbf{T}_{\mathbf{0}}$ & $\mathbf{T}_{\mathbf{1}}$ & $\mathbf{T}_{\mathbf{2}}$ & $\mathbf{T}_{\mathbf{3}}$ \\
\hline Color & 6.73 & 6.67 & 6.81 & 7.52 \\
& \pm 0.19 & \pm 0.16 & \pm 0.14 & \pm 0.22 \\
\hline Taste & 6.51 & 6.73 & 6.95 & 6.81 \\
& \pm 0.16 & \pm 0.19 & \pm 0.09 & \pm 0.08 \\
\hline Texture & 6.67 & 6.51 & 6.57 & 6.86 \\
& \pm 0.08 & \pm 0.16 & \pm 0.08 & \pm 0.19 \\
\hline Flavor & 6.81 & 7.00 & 7.00 & 7.43 \\
& \pm 0.16 & \pm 0.14 & \pm 0.28 & \pm 0.14 \\
\hline Overall Acceptability & 6.67 & 6.72 & 6.83 & 7.14 \\
& \pm 0.16 & \pm 0.19 & \pm 0.22 & \pm 0.14 \\
\hline
\end{tabular}

$\mathrm{T}_{0}=$ Control biscuits without polyphenols extract

$\mathrm{T}_{1}=$ Biscuits with $0.5 \mathrm{~g}$. polyphenols

$\mathrm{T}_{2}=$ Biscuits with $1 \mathrm{~g}$. polyphenols

$\mathrm{T}_{3}=$ Biscuits with $1.5 \mathrm{~g}$. polyphenols

The flavor of all the samples got higher ranking as compared to all the other parameters of biscuits. The highest score (7.43) was achieved by $T_{3}$ which was prepared by adding highest polyphenol concentration, followed by the biscuits of treatments $T_{1}$ and $T_{2}$ which got the similar score (7.00) on the hedonic scale for flavor. However, the lowest ranking on the hedonic scale (6.81) for flavor was noted for the biscuits of $T_{0}$ i.e. without any polyphenols spray. $[16,17]$ reported that polyphenols factors influencing the flavour and other sensory properties and their effects on food and beverage preferences.

The judges were asked to rate the overall acceptability of the final product on the basis of 9-point hedonic scale. The overall acceptability of the biscuits rated first with the maximum score of 7.14 which was prepared from highest polyphenol concentration $\left(1.5 \mathrm{~g}\right.$.) for the treatment $\mathrm{T}_{3}$, followed by the biscuits of the treatment $\mathrm{T} 2$ with score of 6.83. However, the least ranking on hedonic scale (6.67) was noted for the biscuits with no polyphenols i.e. $\mathrm{T}_{0}$. a trend was noted in the overall acceptability of biscuits. The acceptability increased with the increase in polyphenols quantity.

\section{Conclusions}

Consequently, all of the samples prepared with the spray of different concentration of polyphenols acquired good sensory acceptability. However, $\mathrm{T}_{3}$ was highly liked with respect to flavor as well as all other sensory properties. Moreover, polyphenols extracted by microwave assisted drying and ultrasonic bath resulted into maximum total phenol. So it is concluded that the biscuits with 1.5 gram polyphenol concentration are highly acceptable with no bitterness or astringent effect of polyphenols, rather it improved the flavor of biscuits. Hence, they are highly recommended for the people having risks of cancers instead of synthetic polyphenol intake, it will provide them the biscuits with an improved flavor with the medicinal value of anti-cancer effects. Potato peel is considered as waste and it is everywhere. So it is the cheapest source of getting polyphenols.

\section{Authors' contributions}

Conceived and designed the experiments: MT Khan, AS Shah \& N Safdar, Performed the experiments: MT Khan, N Safdar \& H Bilal, Analyzed the data: S Rani, A Basir \& MM Hashim, Contributed reagents/ materials/ analysis tools: MT Khan, SAM 
Shah \& AS Shah, Wrote the paper: S Rani, MM Hashim, A Basir, Z Rahman, SAM Shah \& AS Shah.

\section{Acknowledgments}

The principal author is grateful to NARC Islamabad for providing research facilities. I am very thankful to The University of Swabi, Pakistan for technical support.

\section{References}

1. Sullivan, D (2012). Infant formula and adult/pediatric nutritional methods approved first action using the aoac voluntary consensus standards process. $J$. AOAC Int, 95: 287-290.

2. Latimer, $G$ (2012). Official methods of analysis of aoac international. Gaithersburg, md Aoac international isbn, 978-84-87.

3. Singh, A, Sabally K, Kubow S, Donnelly DJ, Gariepy Y, Orsat V \&Raghavan G (2011). Microwave-assisted extraction of phenolic antioxidants from potato peels. Molecules, 16(3):2218-2232.

4. Kumar, K, Yadav AN, Kumar V, Vyas P \& Dhaliwal HS (2017). Food waste: a potential bioresource for extraction of nutraceuticals and bioactive compounds. Bio and Bioprocessing, 4(1):18.

5. Meda, A, Lamien CE, Romito M, Millogo J $\&$ Nacoulma OG (2005) Determination of the total phenolic, flavonoid and proline contents in Burkina Fasan honey, as well as their radical scavenging activity. Food chem,91(3):571-577.

6. AOAC, (2012). Official Methods of Analysis $17^{\text {th }}$ Edition, Association of Official Agric. Chem. Washington D.C. 1970.

7. Vergara-Valencia, N, Granados-Pérez E, Agama-Acevedo E, Tovar J, Ruales J \& Bello-Pérez LA (2007). Fibre concentrate from mango fruit: Characterization, associated antioxidant capacity and application as a bakery product ingredient. LWT-Food Sci and Tech, 40(4):722-729.
8. Larmond, E(1977). Laboratory methods for sensory evaluation of food. Research Branch, Canada Dept. of Agriculture.

9. Ajila, C, Leelavathi K \& Rao UP (2008). Improvement of dietary fiber content and antioxidant properties in soft dough biscuits with the incorporation of mango peel powder. J Cereal Sci, 48(2):319-326.

10. Ajila, C, Naidu K, Bhat S \& Rao UP (2007). Bioactive compounds and antioxidant potential of mango peel extract. Food chem, 105(3):982-988.

11. Ashoush, I \& Gadallah M (2011). Utilization of mango peels and seed kernels powders as sources of phytochemicals in biscuit. World J Dairy Food Sci, 6(1):35-42.

12. Hooda, S \& Jood S (2005). Organoleptic and nutritional evaluation of wheat biscuits supplemented with untreated and treated fenugreek flour. Food Chem, 90(3):427-435.

13. Chiremba, C, Taylor JR \& Duodu KG (2009). Phenolic Content, Antioxidant Activity, and Consumer Acceptability of Sorghum Cookies. Cereal chem, 86(5): 590-596.

14. hoo, CL \& Aziz NAA (2010). Effects of banana flour and $\beta$-glucan on the nutritional and sensory evaluation of noodles. Food Chem, 119(1):34-40.

15. Alasalvar, C, Al-Farsi M, Quantick P, Shahidi F \& Wiktorowicz R (2005). Effect of chill storage and modified atmosphere packaging (MAP) on antioxidant activity, anthocyanins, carotenoids, phenolics and sensory quality of ready-to-eat shredded orange and purple carrots. Food Chem, 89(1):69-76.

16. Sudha, M, Vetrimani R \& Leelavathi K (2007). Influence of fibre from different cereals on the rheological characteristics of wheat flour dough and on biscuit quality. Food Chem, 100(4):1365-1370.

17. Reddy, V, Urooj A \& Kumar A (2005). Evaluation of antioxidant activity of some plant extracts and their application in biscuits. Food Chem, 90(1):317-321. 